Bond University ePublications@bond

Sports Law eJournal

Faculty of Law

$1-8-2015$

\title{
Maintaining the integrity of the AFL's draft and salary cap systems
}

Chris Davies

James Cook University

Follow this and additional works at: http://epublications.bond.edu.au/slej

Part of the Entertainment, Arts, and Sports Law Commons

Recommended Citation

Chris Davies. (2015) "Maintaining the integrity of the AFL's draft and salary cap systems" , : ISSN 1836-1129.

http://epublications.bond.edu.au/slej/22

This Journal Article is brought to you by the Faculty of Law at ePublications@bond. It has been accepted for inclusion in Sports Law eJournal by an authorized administrator of ePublications@bond. For more information, please contact Bond University's Repository Coordinator. 


\title{
Maintaining the integrity of the AFL's draft and salary cap systems
}

\begin{abstract}
To retain the integrity of its draft and salary cap systems it is essential that the AFL provided suitable penalties for recent breaches of both systems. While COLA has been viewed by its critics as providing the two Sydney clubs additional money under the their salary caps, a suggested compromise is to keep the allowance for players on the lower end of the AFL salary scale, but phase it out for those on the higher salaries.
\end{abstract}

\section{Keywords}

salary caps, the draft system, AFL, Australian Football League, professional sport

\section{Disciplines}

Entertainment, Arts, and Sports Law 


\title{
MAINTAINING THE INTEGRITY OF THE AFL'S DRAFT AND SALARY CAP SYSTEMS
}

\author{
CHRIS DAVIES*
}

To retain the integrity of its draft and salary cap systems it is essential that the AFL provided suitable penalties for recent breaches of both systems. While COLA has been viewed by its critics as providing the two Sydney clubs additional money under the their salary caps, a suggested compromise is to keep the allowance for players on the lower end of the AFL salary scale, but phase it out for those on the higher salaries.

\section{INTRODUCTION}

The Australian Football League (AFL) is undoubtedly one of the most regulated professional sports leagues in the world when it comes to talent dispersion, with both draft and salary cap systems. Each was implemented by the then Victorian Football League (VFL) in the mid-1980s, with this twin system underpinning the growth of the state-based VFL competition to the national AFL competition. Despite the fact that neither the AFL's draft system, ${ }^{1}$ nor its salary $\mathrm{cap}^{2}$ have ever been challenged in court, both systems are still subject to the restraint of trade doctrine. This means that in order to protect the legal validity of its systems, the AFL is required to prove they help to obtain its stated objective of a more even competition, ${ }^{3}$ and also that it is not unreasonable on the players. The use of these two labour market control systems has not been without incident, including suggestions arising in mid-2012 that Melbourne Demons had been involved in deliberately losing games during the 2009 season in order to qualify for a priority draft selection. Later in 2012 it was also revealed that there had been both draft and salary cap issues with Adelaide Crows player, Kurt Tippett, whilst another issue has been the near $10 \%$. Cost of Living Allowance (COLA), additional to the standard salary cap, allocated to the two Sydney clubs.

* Associate Professor, School of Law, James Cook University. The author would also like to disclose that he is a member of the Sydney Swans.

1 For discussion of the use of draft systems by professional sporting leagues see Chris Davies, 'Draft Systems in Professional Team Sports and the Restraint of Trade Doctrine' (2006) 1 Australian and New Zealand Sports Law Journal 80-102; Chris Davies, 'Labour Market Controls and Sport in Light of UEFA's Financial Fair Play Regulations' (2012) 33 European Competition Law Review 435.

2 For a discussion on salary caps see Antonio Buti, 'Salary Caps in Professional Team Sports: an Unreasonable Restraint of Trade' (1999) 14 Journal of Contract Law 130; Chris Davies, 'The Use of Salary Caps in Professional Team Sports and the Restraint of Trade Doctrine, (2006) 22 Journal of Contract Law 246-247; Chris Davies, 'Salary Cap Scandals in Australian Sport' (2011) 11 International Sports Law Review 30-36; Chris Davies, 'The Financial Crisis in the English Premier League: Is a Salary Cap the Answer?' (2010) 31 European Competition Law Journal 24-30.

3 For discussion on whether the AFL has created an even competition see Chris Davies, 'The AFL's Holy Grail: the Quest for an Even Competition' (2005) 12 James Cook University Law Review 65-92. 
This article will examines these controversies and breaches of the AFL's draft and salary cap systems, and analyses whether the subsequent penalties handed out by the AFL were appropriate. It will also examine the issues relating to COLA in regard to the salary cap. First, however, it will examine the father-son rule component of the AFL draft which, while it never became an issue, always had the potential to do so.

\section{THE RECENT AFL DRAFT ISSUES}

\section{The father-son rule}

The father-son rule allows the sons of former players who played the required number of games for a club, presently 100, to be selected by that club without having to go through the usual draft process. This system is designed to encourage clubs to select players who may have a strong sentimental attachment to that club. While there has never been any actual legal issues arising from this rule, it is suggested that one could have arisen if any club had ever obtained an advantage from its selections under this rule, which would be contrary to the primary objective of an even competition.

The club that has undoubtedly obtained the most value from the father-son rule in recent years has been the 2007, 2009 and 2011 premiers, Geelong Cats, who had up to three players acquired under this rule in each of these premiership teams. It is suggested that the main problem was not so much that Geelong had more such selections than any other AFL premiers, but rather the draft selections Geelong was required to use in order to acquire these players. This is because, under the rules at the relevant time, Geelong only used third round draft selections ${ }^{4}$ in order to obtain the services of Gary Ablett (overall pick number 40 of the 2001 draft), Matthew Scarlett (no 45, 1997), Nathan Ablett (no 48, 2004) and Tom Hawkins (no 41, 2006). This meant (indicated that) therefore that Geelong still had their first and second round draft selections in each of these years to obtain the services of other premiership players, such as Jimmy Bartel $($ no 8, 2001) and Joel Selwood (no 7, 2006). It is not suggested that it was only because of this rule that Geelong were able to recruit a team capable of winning multiple premierships. However, it is also clear that Brownlow Medallist Gary Ablett and All-Australians, fullback Matthew Scarlett and full-forward Tom Hawkins, were all players likely to have been first round selections. This therefore meant Geelong effectively had an extra first round selection in each of these drafts, raising the possibility that the system gave one club an advantage, contrary to the AFL's intended objective of a more even competition.

As a result it was essential that the father-son rule was amended in relation to which draft selections were to be used in order to obtain the services of a particular player. Amendments to the rule made in 2007 mean that the draft selection now required to be used is based on which selection other clubs would have been willing to use to obtain that player's services. ${ }^{5}$ For example, in the 2011 National Draft, the Sydney Swans had to select Tom Mitchell with its first round selection, no 21 overall, as Fremantle had indicated that it would select him with its first round selection. Similarly, Essendon had to use its first round selection in the 2012 National

4 The rules for many years involved clubs having to use a third round selection for their first father-son selection and a second round selection if selecting more than one player under this rule. Geelong, for instance, also selected Marc Woolnough under the father-son rule with a second round selection, No 29 overall, in the 1997 National Draft as well as Matthew Scarlett with its third round selection.

5 AFL amends father/son rule (25 April 2007) Australian Broadcasting Corporation $<$ http://www.abc.net.au/news/2007-04-25/afl-amends-fatherson-rule/2532570> 
Draft, no 10 overall, in order to obtain the services of Joe Daniher as other clubs had indicated they would use their first round selections to draft him.

From a player's perspective it should also be noted that a player eligible for selection under the father-son rule does not have to agree to go to that club. Marc Murphy, for instance, was eligible for selection by the Brisbane Lions under the rule, and despite Brisbane's interest, Murphy decided instead to nominate for the 2005 National Draft where he was selected by Carlton as the No 1 draft selection.

The father-son rule finds support as an essential component of the AFL draft system as it eliminates the possibility of a player with a genuine emotional attachment to a particular club potentially taking legal action in order to be able to play for that club. ${ }^{6}$ The criticism levelled at the rule stemmed from previous situations, where clubs were able to obtain players good enough to be first round selections with later round selections, potentially undermining the objective of the draft system. Smarrini, for instance, has suggested that a hypothetical team consisting of players selected under the father-son rule would be superior to a team made up of number one draft selections. ${ }^{7}$ It is suggested, however, that with the rule changes, the AFL has found the balance between enabling players to join their father's club, but at the same time not disadvantaging the other clubs in the competition.

While the father-son rule has been suitably modified before ever becoming a draft issue, similar issues have arisen regarding 'tanking': the suggestion that clubs may deliberately lose games in order to obtain priority draft selections has the potential to undermine the integrity of both the competition and the draft.

\section{The AFL priority selections: the Melbourne 'tanking' issue}

Priority selections in the AFL's draft system involve clubs being considered eligible for extra draft selections, usually prior to the first overall selection in the draft, with this eligibility being determined by not winning a certain number of matches. The rules regarding qualification for such a selection have varied over the years. For some drafts it was obtained if a club did not win more than four matches in that particular season, while at other times it has been based on the combined results of two seasons, namely no more than eight matches across those two years. These rules potentially allowed for a bottom placed club to acquire the first two selections in the draft, a priority selection plus the first overall selection. This, for instance, was what Melbourne Demons obtained in the 2009 National Draft, selecting Tom Scully with a priority selection and Jack Trengrove with the first overall selection.

However, the circumstances in which Melbourne received this double pick later raised certain concerns, particularly in regard to how players were seemingly selected, and played, out of position during the latter part of the season. These unusual tactics became the subject of public speculation, ${ }^{8}$ to the point where an investigation was ordered by the AFL after a former Melbourne player, Brock McLean, indicated that the reason he left the club at the end of the 2009 season was because he had been uncomfortable with the way in which the club had, in his

6 Note than one of the challenges to the then VFL's residential zone involved Peter Hall, who was zoned to Collingwood but whose father had played for South Melbourne - though not enough games for Hall to be selected under the father-son rule. The rules were then held to be an unreasonable restraint of trade on Hall: Hall v Victorian Football League [1982] VR 64.

7 Gus Smarrini, ‘No 1 Draft Selections v Father-Son: Nature or Nurture', AFL Record, 31 May 2014, 57.

8 Jay Clark, 'Demon drama mounts', The Telegraph, 4 January 2013, 85. 
opinion, approached the games during the latter part of that season. It was McLean's opinion that the club was putting too much emphasis on obtaining a priority selection in the upcoming national draft by trying to ensure it did not win more than the required number of matches. To McLean this emphasis went against what he had been taught as a player, which is why he sought a trade to Carlton Football Club. ${ }^{9}$

An inquiry into these allegations was subsequently made by the AFL's Integrity Department, with the five month long investigation resulting in Melbourne being fined $\$ 500$ 000, though the club was 'not fined for tanking, but because the "club has to bear the responsibilities of its agents."'10 This was because the AFL accepted that the club's Chief Executive, Cameron Schwab, and the Melbourne Board had 'ultimately no knowledge' of the football department's activities. ${ }^{11}$ However, Melbourne's coach at the time, Dean Bailey, was suspended for the first 16 weeks of the 2013 season for engaging in 'conduct prejudicial to the interests of the AFL.' 12 Chris Connolly, Melbourne's general manager of football operations at the relevant time, was suspended for 12 months. The reason for Connolly receiving the heaviest penalty was that he had made statements regarding the team's performances in a football department meeting and indicated 'a desire to secure a priority pick'.$^{13}$ Employees at Melbourne later gave evidence that following this meeting they felt their jobs were in jeopardy if they did not comply with Connolly's wishes. ${ }^{14}$

The penalties were further put in perspective by the AFL's Gillon McLachlan, who stated that as Bailey had always done all he could to win the actual matches, there had been 'no tanking on match day' ${ }^{15}$ Thus, it appears the AFL's definition of tanking is restricted to not endeavouring to win on match day, with team selection and the adoption of certain tactics in the lead-up to games falling outside of the AFL's definition, notwithstanding that such factors may affect the performance of the team on match day.

While not everyone was satisfied with the AFL's determination of what actually constitutes tanking, it is suggested that Melbourne's example indicates that tanking does not necessarily work. In the four seasons since 2009 the club has finished no better than twelfth, including slumping to seventeenth in the eighteen team 2013 season. This suggests that creating a winning culture can be far more important than obtaining one additional priority draft selection. Melbourne's plight, for instance, can be compared to 2012 Premiers, Sydney Swans, a club that has missed the finals just twice since 1996. It should be noted that the previous year Sydney would have been eligible for a priority selection - had they lost the last match of the 1995 season. However, they won that match; the win not only giving the club momentum into the next season where it reached the Grand Final, but could be seen as the beginning of establishing a winning culture which has led to three more Grand Final appearances since, including two premierships.

It is further suggested that while this priority selection system has been a contentious one for the AFL, it is still a system that may be needed in order to help prevent clubs from experiencing too many poor seasons at the bottom of the AFL ladder. However, relying on a secret formula, rather than being based on a set number of losing games, may prove to be a superior system, as it

9 On the Couch, Fox Sports, 15 July 2013.

10 Greg Denham, 'Two suspensions and a $\$ 500,000$ fine, but not for tanking', The Australian, 20 February 2013, 36 .

11 Ibid.

12 Greg Denham, 'Crows claim Bailey ban is unfairly punishing club,' The Australian, 21 February 2013, 32.

3 Above $n 10$.

14 Ibid.

15 Ibid. 
would help retain the integrity of the draft system and ensure that only clubs in genuine need will receive them. This was the approach taken by the 2012 priority pick reforms, which scrapped automatic priority picks for poorly performing teams. Picks are now awarded on a discretionary basis by the AFL, which follows a confidential performance-based formula. ${ }^{16}$

While the tanking issue received considerable media attention, so too did the another recent issue involving the AFL draft system, namely the 'get out' clause contained in Kurt Tippett's contract with Adelaide.

\section{The Kurt Tippett contract}

At the end of the 2012 season, Adelaide Crows forward Kurt Tippett indicated he wished to leave the club and join reigning premiers, the Sydney Swans. Negotiations commenced during the trade period of the national draft between the two clubs, though Sydney stated it was not willing to trade any of its premiership players, eventually offering Adelaide its first round draft selection and another player, Jesse White. However, due to the fact Sydney had just won the premiership and the inclusion of compensation selections for clubs which had lost players to expansion sides Gold Coast and Greater Western Sydney, Sydney's first round draft selection was only no. 22. While Adelaide was close to agreeing to the proposed trade deal, coach Brenton Sanderson decided against it, claiming it was insufficient compensation for a player of Tippett's ability.

However, what was then revealed by Tippett's legal representatives was the presence of a clause in his contract whereby Adelaide had to accept an offer of a second round draft selection, should he ever wish to leave the club. It should be noted this type of 'get out' clause is often used in professional team sports. For instance, in the English Premier League (EPL), Newcastle had to allow Demba Ba to move to Chelsea in the 2013 January transfer window after the release transfer fee of $£ 7.5 \mathrm{~m}$ stated in his contract was agreed to by Chelsea. ${ }^{17}$ However, in a code that operates under a draft system, Tippett's clause was seen as manipulating the draft, and therefore in breach of AFL rules. ${ }^{18}$

An investigation was then commenced, and while ideally the AFL would have liked to have made a decision on the matter before the 2012 national draft, natural justice required that the parties had sufficient time to prepare their cases. Adelaide, however, took pre-emptive action by banning itself from the first two rounds of the 2012 draft. ${ }^{19}$ This then prevented the AFL from the potentially embarrassing situation of imposing draft sanctions in a hearing that was to take place a week or so after the draft.

When the hearing eventually took place, Adelaide was found guilty of draft manipulation, and also breaches of the salary cap rules relating to third party payments. It was fined $\$ 500,000$ on top of the self-imposed draft sanctions, while CEO Steven Trigg was banned from operating in the AFL for six months. Tippett himself did not escape punishment, being suspended for the first 11

16 Mark Robinson, 'AFL concedes Melbourne could receive priority pick, and if it loses James Frawley could have top three draft selections', The Herald Sun (Online), April 92014 $<$ http://www.heraldsun.com.au/sport/afl/afl-concedes-melbourne-could-receive-priority-pick-and-ifloses-james-frawley-could-have-top-three-draft-selections/story-fni5f91a-1226879331080?nk=56f3550 bdee21c9f00f910fe3208ed2e>

17 For discussion of these clauses see Chris Davies, 'Football's Transfer System Post-Bosman: Freedom of Movement for Players versus Football's Financial Future?' (2014) 35 European Competition Law Review 8.

18 Emma Quayle, 'Crows, Tippett caught in \$200,000 rort', The Age, 26 October 2012 $<$ http://www.theage.com.au/afl/afl-news/crows-tippett-caught-in-200000-rort-20121025-287t7.html>

19 Courtney Walsh, 'Crows in draft bid to ease sanction,' The Australian, 22 November 2013, 36. 
rounds of the 2013 season, though he did achieve his goal of moving to the Sydney Swans when he was selected by the club in the pre-season draft.

The penalties handed out to Adelaide were consistent with, for instance, those handed out to Melbourne, with it being further suggested these penalties were essential in order to retain the integrity of the AFL draft. Unlike Melbourne, however, Adelaide was also guilty of salary cap breaches in regard to Tippett. What will now be discussed are these salary cap breaches involving Adelaide and Tippett, and the issues relating to the Cost of Living Allowance (COLA).

\section{THE SALARY CAP ISSUES}

\section{The Kurt Tippett contract}

When AFL commenced investigation into the Tippett situation it was revealed that the player had been receiving $\$ 300,000$ from undisclosed third party payments, in breach of the AFL's salary cap, in addition to the draft manipulation issue. ${ }^{20}$ This further breach contributed to the hefty suspensions handed out by the AFL, and again, it is suggested that penalties were required for the salary cap breaches, not only to retain the integrity of the system, but also for consistency with other penalties for breaching the salary cap. Carlton Football Club, for instance, previously incurred heavy fines and were denied draft selections for salary cap breaches. ${ }^{21}$

However, the Tippett saga did not stop with the AFL's investigation, and the subsequent signing of Tippett by the then reigning premiers, the Sydney Swans, raised another issue relating to the salary cap, namely COLA.

\section{The cost of living allowance}

The COLA provided the means for the AFL to add an extra 9.8 percent to the salaries of players from Sydney teams to compensate for Sydney's higher cost of living, particularly in relation to housing, both in terms of rental and the purchasing of properties.

It should be noted that this is not a new aspect of the salary cap, and it was in operation at the time the Sydney Swans won the 2005 AFL Premiership. It also appears that it was not so much that it won the premiership again in 2012 that raised concerns from other clubs, but the fact that it was able to sign the high earning Tippett. Carlton chief executive Gregg Swann, for instance, made the comment that 'we [Carlton] are staggered that the premiers can add an $\$ 800,000$ player to their list without shedding anyone. The only way they can do that is the allowance and we think it is not right. It's not how the system is meant to work'.22 These comments brought immediate condemnation from both Sydney Swans chairman, Richard Colless, and Greater Western Sydney Giants chairman, Tony Shepherd, both of whom stoutly defended the allowance, and countered it should be raised to reflect the true disparity between Sydney and the rest of Australia. ${ }^{23}$

It should be pointed out that the Carlton chief executive's comments regarding the Sydney Swans' ability to sign Tippett 'without shedding anyone' were not accurate, as at the end of the

20 Ibid.

21 For discussion see Chris Davies, 'Salary Cap Scandals in Australian Sport' (2011) 11 International Sports Law Review 30.

22 Swans, Giants simmer after Carlton's 'cost of living' attack (4 March 2013) Australian Football League http://www.afl.com.au/news/2013-03-04/punish-carlton-chief.

23 Ibid. 
2012 season the Sydney Swans had either delisted or traded Mark Seaby, Jarrod Moore, Brett Meredith, Dennis Trent-Lane, Matt Spangher and Campbell Heath, none of whom were in its Grand Final team, yet collectively were earning close to a million dollars a year. It was the removal of these salaries which then allowed the Sydney Swans to sign Tippett, before replacing these players with those on much lower salaries, the cost of which was covered by the annual increase in the salary cap. It was also suggested that Swann's comments showed a lack of understanding of the principles underlying COLA, as the allowance is designed to maintain an even playing field by compensating players for the extra costs of living in Sydney.

However, the 2013 signing by the Sydney Swans of star forward Lance Franklin on a nine-year deal worth nearly $\$ 10$ million raised further debate about COLA and whether it should continue. ${ }^{24}$

Like any aspect of the draft system and salary cap, COLA must be examined in relation to the restraint of trade perspective. There is little doubt that for a salary cap to help achieve its stated objective of creating a more even competition it should be even for all clubs, as an uneven salary cap is less likely to achieve that objective. ${ }^{25}$ The question then is whether this extra $9.8 \%$ creates an uneven salary cap in favour of the two Sydney clubs. Alternatively, would its removal create an uneven cap by forcing the two Sydney clubs to work with a salary cap that, in net terms, would be nearly $10 \%$ less than the other clubs?

It is suggested that what many of the Melbourne based critics ${ }^{26}$ of the allowance have also not taken into consideration is the players' perspective, having instead approached it purely from a club viewpoint. Under the present AFL rules, players first entering the competition have no choice but to go to the club that drafts them. If that happens to be one of the Sydney clubs that means they will, in net terms, be earning around 10\% less than if drafted by one of the other clubs. This could be considered unreasonable on the player, and arguably in breach of the second requirement of the restraint of trade doctrine, namely that the restraint not be unreasonable on the players. The reason for this is that any new draftee will be on a salary at the lower end of the AFL scale, where $10 \%$ is a significant difference. It is therefore suggested that players effectively forced to live in Sydney under the draft system must be compensated for being financially affected by its higher cost of living. Conversely, it is also acknowledged that a player such as Buddy Franklin, earning reportedly close to $\$ 1$ million a year, will not be as significantly affected by Sydney's extra cost of living.

The author would therefore propose a compromise between the present situation, and the total dismantling of COLA. The suggestion is that the AFL continue COLA assistance to players on the lower end of the salary scale, by continuing to financially upgrade all players' contracts allowing a salary of $\$ 200,000$ per year by the $9.8 \%$ presently allowed under COLA. It is then recommended that for contracts over this amount COLA is still implemented, but on a sliding scale for contracts valued up to $\$ 400,000$ per year. Players earning more than this limit would not be compensated. This would emphasise that it is the players who are assisted, rather than the two Sydney clubs receiving nearly $10 \%$ extra for their salary cap. It would also enable the AFL to top up the salaries

24 See, for example, Jake Niall, 'Buddy's mega-deal brings the AFL's COLA wars back into the spotlight', The Age (Online), 2 October 2013 < http://www.theage.com.au/afl/afl-news/buddys-megadeal-brings-theafls-cola-wars-back-into-the-spotlight-20131001-2ur08.html>.

25 Antonio Buti, 'Salary Caps in Professional Team Sports: an Unreasonable Restraint of Trade' (1999) 14 Journal of Contract Law 130, 146.

26 Above $\mathrm{n} 22$. 
of the players directly affected by Sydney's higher living costs, but prevent it being viewed as a means of paying players like Tippett and Franklin more money than what other clubs can under the salary cap. It is suggested that this may actually happen since, at the time of writing, it appears that while COLA in its present form will be phased out by 2016, Sydney players on the lower salaries may still be eligible for the allowance. ${ }^{27}$

\section{CONCLUSION}

The AFL's twin draft and salary cap systems have undoubtedly been important to its growth over the last few decades. However, it is essential for the integrity of the two systems and the competition as a whole that suitable penalties be handed out to the clubs, officials and players actively involved in any breach of either system. While COLA has been viewed by its critics as providing the two Sydney clubs additional money under the their salary caps, the players' perspective is also important, and a suggested compromise is to keep the allowance for players on the lower end of the AFL salary scale, but phase it out for those on the higher salaries.

27 Greg Denham, 'Low-paid Swans in line for allowance', The Australian, 6 March 2014, 31. 